MEDICINE AND THE LAW

\title{
Obstetric risk avoidance: Will anyone be offering obstetrics in private practice by the end of the decade?
}

\author{
G R Howarth \\ Graham Howarth is a medico-legal advisor and Head of Medical Services for Africa at the Medical Protection Society, United Kingdom.
}

Corresponding author: G R Howarth (graham.howarth@mps.org.uk)

Obstetric claims inflation is increasing the cost of covering obstetric risk. This is leading to obstetric risk avoidance by those offering insurance and by practitioners who do not perform enough deliveries to cover the cost of obstetric risk indemnity. By the end of the decade indemnifying obstetric risk will probably be too expensive for doctors in private practice. Non-indemnified doctors will be unable or unwilling to do private deliveries; however, women will still fall pregnant and require delivery. These women will inevitably be forced to deliver in provincial facilities, shifting the workload and liability to the state.

S Afr Med J 2013;103(8):513-514. DOI:10.7196/SAMJ.7233

'It has never been safer to have a baby and never been more dangerous to be an obstetrician' ${ }^{[1]}$

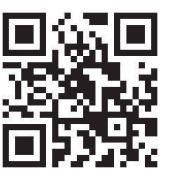

Who will deliver our grandchildren? This is a question asked in an excellent American article on cerebral palsy and subsequent litigation. ${ }^{[1]}$ The issue may be more pressing in South Africa (SA), the salient question being - 'who, if anyone, will be performing deliveries in private practice by the end of the decade?' If the answer to the question is 'nobody', the consequences will extend beyond private healthcare. There are also serious implications for the state sector that will require addressing.

Understandably obstetric-related claims are usually high-value claims that run into the millions of rand. While the risk of an obstetric claim to an individual obstetrician may be relatively low, the value of a claim is so high that an individual cannot possibly afford to compensate a claimant adequately should things go amiss. The financial risk has to be transferred either to an insurer or shared by a non-profit indemnifier.

Insurance companies, although offering an insurance product, also have responsibilities to their shareholders, who have invested in them, to offer a return on investments - they need to generate a profit. A non-profit mutual indemnifier is not burdened with having to secure a profit for shareholders, as there are no shareholders. Both models, however, require sufficient reserves to meet future administrative and claims costs. Anybody subscribing to one of these organisations needs to be sure that the organisation has sufficient funds to meet the cost of future claims; rates need to be determined according to risk.

As obstetric risk has been insured, and some insurers remain in the market, it is clear that obstetric risk is not uninsurable. Claims inflation, however, makes it more difficult to remain affordable and realise a profit when insuring obstetric risk. Insurers are leaving the obstetric market - they are avoiding obstetric risk. Obstetric risk is not uninsurable, but to remain profitable it is becoming unaffordable. As non-profit mutual organisations are not burdened by profit generation they can remain affordable for longer.

An insurer leaving the obstetric market is not without potential consequences. Negligence insurance is usually purchased on a claims- made basis. For a claim on a particular incident to be successful, the insured either has to have been insured at the time of the incident and still be insured by the insurer when the claim is made or at least have reported the incident to the insurer, while still insured. If an insurer has decided to avoid obstetric risk, the insurer may decide not to offer runoff cover so that the previously insured obstetrician is no longer covered for incidents that occurred while they were insured, if the incident was not reported prior to the withdrawal of cover. Should run-off cover not be available the obstetrician will be uninsured for all unreported incidents - this would have major implications for potential claimants. The alternative indemnity model of an occurrence-based product does not have the same consequences. In the occurrence-based model, as long as the doctor was appropriately indemnified at the time of the incident the right of seeking assistance is not time limited and remains even if the cover ceases.

The natural progression of an obstetric and gynaecology practice tends to mature from obstetrics to gynaecology. Newly-qualified, young practitioners usually attract younger patients and have practices dominated by obstetrics. Satisfied patients remain with the practitioner and the practice's emphasis slowly shifts to gynaecology; it is not unusual to find a practitioner nearing retirement who does virtually no deliveries. Now that indemnity rates are so high, a practitioner has to have a substantial obstetric practice to recover their indemnity costs. Experienced practitioners, whose practices have matured, no longer perform enough deliveries to afford the high cost of indemnity and doubtless this will accelerate the decision to stop obstetrics in some cases - another form of obstetric risk avoidance.

Recently qualified obstetricians and gynaecologists entering private practice are also confronted with a problem. Given the high indemnity rates, they need to deliver a substantial number of patients to cover their costs. Those entering private obstetric practice and those nearing retirement, at the extremes of practice, are affected first and tend to avoid obstetric risk.

Young doctors are aware of these problems and there is a concern that young practitioners will also avoid obstetrics and gynaecology as a career choice as they realise that their career options in private practice are severely curtailed - another form of obstetric risk avoidance. ${ }^{[2]}$ Not only will that disrupt the age distribution of 
obstetricians and gynaecologists, but it also means that these keen, hard working young doctors will not be available to public service as trainees in obstetrics and gynaecology.

What about the bulk of established obstetricians and gynaecologists in private practice? The threshold making obstetric indemnity unaffordable is not a universal threshold but dependent upon individual practice. ${ }^{[3]}$ How keen is the doctor to maintain an obstetric practice and how many deliveries are performed? It is difficult to predict what subscription rates will be by the end of the decade, but extrapolation of current subscription rate inflation, reflecting obstetric risk, suggests subscription rates may be unaffordable to all by the end of the decade. That being the case, those performing deliveries privately will be unable to transfer their financial obstetric risk. Insurers will leave the market first, unable to make a profit without becoming unaffordable. Non-profit mutual organisations may remain in the market but they will become progressively unaffordable as their subscription rates reflect the obstetric risk.

Practitioners unable to transfer, and thus meet, the financial burden of an obstetric claim would be ill advised to continue offering an obstetric service. Indeed, it is unlikely that private hospital groups would allow uninsured or non-indemnified obstetricians to perform deliveries in their hospitals. The state is also clearly concerned that doctors should be adequately insured or indemnified to meet their responsibilities. ${ }^{[4]}$

Although difficult to quantify, there are as many as 137000 private deliveries annually in SA. ${ }^{[5]}$ In the vast majority, the mother will use the services of private healthcare professionals. In descending order of frequency these deliveries will be performed by obstetricians, general practitioners and midwives - all in private practice. In the absence of adequate indemnity or insurance nobody will perform private deliveries.

Private patients will still become pregnant and have to deliver and only one provider will be able to afford the financial risk of obstetrics - the state. ${ }^{[3]}$ What does this mean numerically? There were 1294694 live births registered for 2010, of which an estimated 136934 occurred privately. ${ }^{[5,6]}$ This would increase the burden on already busy provincial facilities by $10,6 \%$; put alternatively, given Chris Hani Baragwanath Hospital (CHBH) performs 17000 deliveries a year, another 8 facilities with the obstetric capacity of $\mathrm{CHBH}$ would be required. ${ }^{[7]}$ Additionally, the state facilities are not well distributed to cater for these new parturients, the majority of whom would deliver in the larger urban areas. Using the $\mathrm{CHBH}$ analogy, Gauteng would require an additional 3 obstetric units, KwaZulu-Natal 2, and the Western and Eastern Cape 1 additional obstetric unit each. The increased obstetric load would be disproportionately placed on the state obstetric units that already act as busy referral services for the rural areas. The attention of these state facilities will be diverted from those who they were primarily intended to serve.
Equally, if not more importantly, not only will the workload migrate across to the state, but also the liability; there will be a transfer of the obstetric financial risk to the state. The state already has its hands full with litigation and doubtless this will substantially increase the burden. The state does not budget independently for litigation successful litigation cases are paid out of the health budget. Every rand lost to successful litigation is a rand lost to public care ${ }^{[8]}$ Already overburdened facilities will have to cope with demanding patients; the system will be placed under increased stress, probably resulting in increased litigation that will use up the money that could have been used to improve the system. ${ }^{[8]}$

The consequence of obstetric risk avoidance will be that no deliveries will be performed privately, and private patients will have to deliver in provincial facilities. The financial risk of obstetric liability will also migrate to the state. Concerns about increasing litigation have already been raised in local professional publications, but as yet have not entered the public arena. ${ }^{[3,8,9]}$ This is primarily a problem for the public and politicians who need to be well advised on the options and potential consequences of their decisions. The SA Government, which has already started to investigate the problem, will have to make some difficult decisions quickly. Failure to react decisively is in itself a choice, which may have serious consequences for private parturients in the not too distant future.

A similar rapidly-approaching fate awaits patients requiring private spinal and neurosurgery.

Conflict of interest. GRH is a full-time employee of the Medical Protection Society. The Medical Protection Society is not an insurance company but a non-profit mutual organisation that offers occurrence-based indemnity to healthcare practitioners.

\footnotetext{
1. MacLennan A, Nelson KB, Hankins G, Speer M. Who will deliver our grandchildren? Implications of cerebral palsy litigation. JAMA 2005;294(13):1688-1690. [http://dx.doi.org/10.1001/jama.294.13.1688] Koller AB (as SASOG President). Letter to Minister of Health regarding the consequences of increasing

2. Koller AB (as SASOG President). Letter to Minister of Health regarding the consequences of increasing
litigation. 25 April 2011 .
3. Howarth GR. The threat of litigation: Private obstetric care - quo vadis? S Afr J BL 2011;4(2):85-88.

3. Howarth GR. The threat of litigation: Private obstetric care - quo vadis? S Afr J BL 2011;4(2):85-88.
4. Bateman C. Clumsy patient-friendly regulations could strip 25000 of MPS cover. S Afr Med J 4. Bateman C. Clumsy p
2010;100(11):696-697.

5. Meyer ME, Swanepoel DW. Newborn hearing screening in the private health care sector - a national survey. S Afr Med J 2011;101(9):665-667.

6. Statistics South Africa. Recorded live births 2011. Statistical release P0305. Pretoria: Statistics South Africa, 2012. http://www.statssa.gov.za/Publications/P0305/P03052011.pdf (accessed 4 July 2013).

7. http://www.chrishanibaragwanathhospital.co.za/departments/obstetrics_and_gynaecology (accessed 4 July 2013).

8. Malherbe J. Counting the cost: The consequence of increased medical malpractice litigation in South Africa. S Afr Med J 2013;103(2):83-84. [http://dx.doi.org/10.7196/SAMJ.6457]

9. Pepper MS, Slabbert MN. Is South Africa on the verge of a medical malpractice litigation storm? S Afr J BL 2011;4(1):29-35.
}

Accepted 4 July 2013. 